\title{
$U$ norden
}

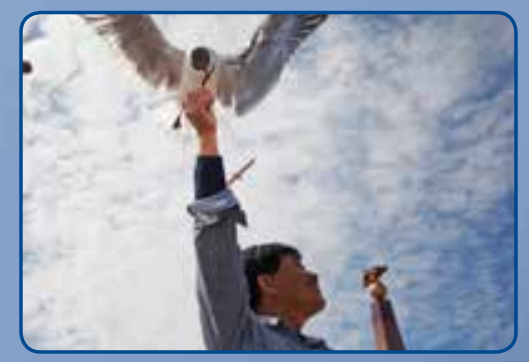

SEKTORPROGRAM

\section{Kultur}

Finlands ordförandeskap i

Nordiska ministerrådet 2016 
norden 


\section{Sektorprogram kultur}

Program för Finlands ordförandeskap i Nordiska ministerrådet 2016

ISBN 978-92-893-4519-4 (PRINT)

ISBN 978-92-893-4520-0 (PDF)

http://dx.doi.org/10.6027/ANP2016-717

ANP 2016:717

(C) Nordiska ministerrådet 2016

Layout: Jette Koefoed

Omslagsfoto: ImageSelect och Karin Beate Nøsterud

Foto: s. 6 Signelements; s. 8 Benjamin Suomela;

s. 12, s. 16 Johannes Jansson; s. 14, Mette Mjöberg Tegnander Typsnitt: Meta LF

\section{www.norden.org/nordpub}

\section{Det nordiska samarbetet}

Det nordiska samarbetet är ett av världens mest omfattande regionala samarbeten. Det omfattar Danmark, Finland, Island, Norge och Sverige samt Färöarna, Grönland och Åland.

Det nordiska samarbetet är politiskt, ekonomiskt och kulturellt förankrat och är en viktig partner i europeiskt och inter nationellt samarbete. Den nordiska gemenskapen arbetar för ett starkt Norden i ett starkt Europa.

Det nordiska samarbetet ska stärka nordiska och regionala intressen och värderingar i en global omvärld. Gemensamma värderingar länderna emellan bidrar till att stärka Nordens ställning som en av världens mest innovativa och konkurrens kraftiga regioner.

\section{Nordiska ministerrådet}

Ved Stranden 18

DK-1061 København K

Telefon (+45) 33960200

\section{www.norden.org}


SEKTORPROGRAM

\section{Kultur}

Finlands ordförandeskap i

Nordiska ministerrådet 2016

Förord

1. Ett öppet och innovativt Norden 9

2. Det hållbara Norden 11

3. Det kreativa Norden 11

4. Det interkulturella Norden 13

5. Det unga Norden 15

6. Det digitala Norden 17

Preliminärt kalendarium för $2016 \quad 18$ 


\section{Förord}

Vatten-natur-människor är det gemensamma övergripande temat för Finlands ordförandeskap inom Nordiska ministerrådet 2016.

Omsorg om naturen och miljön, en enhetlig ekonomisk region, en vital och dynamisk kultur, språklig variation, öppen och tillgänglig data, allemansrätt, medborgarsamhälle och en starkt rotad demokrati är karaktäristiska drag för alla de Nordiska länderna.

Kulturen förenar oss nordbor. Den är också en grundpelare i det officiella nordiska samarbetet med utgångspunkt i Helsingforsavtalet från 1962. Gemensamt för oss i Norden är även kulturens öppenhet. Vi har samma förståelse dess egenvärde, samtidigt som den är värdefull med tanke på vår välfärd och samhörighet.

Vi vill att alla invånarna i Norden känner sig som hemma i Norden och att även den nordiska kulturen upplevs som något som man identifierar sig med. Vi hoppas att kulturen och konsten ska bidra till att våra nyanlända integrerar sig och inkluderas i sitt nya hemland, och att dessa aspekter även skulle hjälpa dem att känna sig välkomna här hos oss.

Den nya teknologin har medfört konst- och kultursektorn en öppenhet och transparens samt nya sätt att skapa, uppleva och konsumera. I bästa fall bidrar digitaliseringen till ännu bättre åtkomst av kulturtjänster; till en öppenhet och tillgänglighet av dessa.

Det finns ett stort intresse ute i världen för våra respektive kulturer, något som också underlättas av att samarbetet mellan olika aktörer i våra länder löper smidigt.

Under ordförandeskapsåret vill vi på undervisnings- och kulturministeriet lyfta fram ett synsätt där människan står i centrum och reflektera kring temat det öppna Norden - det digitala Norden. Vi samarbetar med social- och hälsovårdsministeriet samt arbets- och näringsministeriet kring ett treårigt sektorövergripande prioriteringsprojekt under devisen Ett öppet och innovativt Norden med välmående människor 2020. Projektets genomgående teman är kultur, välfärd och jämlikhet. 
I år förverkligar vi dessutom inom ramen för strategin för Nordiska ministerrådets kultursamarbete för 2013-2020 vårt sektorprogram med utgångspunkt i de teman som strategin bygger på - det hållbara Norden, det kreativa Norden, det interkulturella Norden, det unga Norden och det digitala Norden. Strategin står för kulturministrarnas framtidsvision, och anger riktlinjerna för syftet med det nordiska samarbetet inom kultursektorn.

Under vårt ordförandeskapsår kommer vi att betona stora projekthelheter, som presenteras närmare i detta sektorprogram. Projekt, som förhoppningsvis lever i tiden och svarar mot våra gemensamma behov. Vissa av dessa projekt är även kontinuum av tidigare projekt under andra ordförandeskap.

Jag hoppas att vårt år som ordförandeland stannar i minnet hos er som en tid av samförstånd och öppenhet.

Härmed vill jag önska alla nordbor ett inspirerande kulturår 2016!
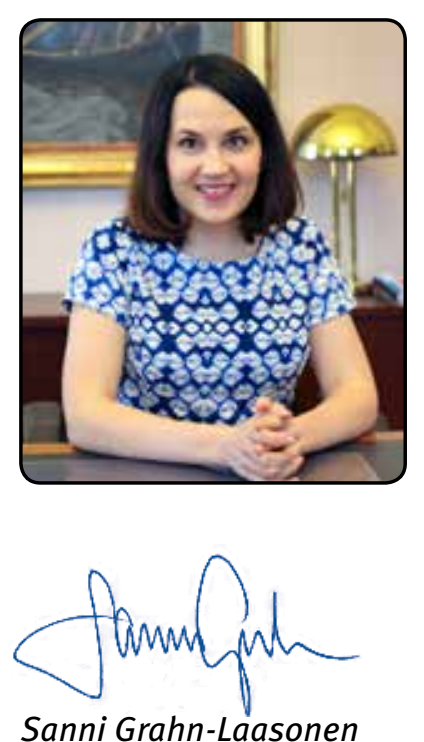

undervisnings- och kulturminister 


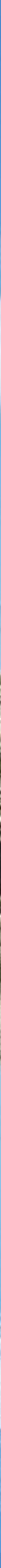




\section{Prioriteringsprojektet "Ett öppet och innovativt Norden med välmående människor 2020 - jämlika möjligheter till välmående, kultur, utbildning och arbete" 2016-2018}

Social- och hälsovårdsministeriet, arbets- och näringsministeriet och undervisnings- och kulturministeriet i Finland förverkligar gemensamt ett treårigt prioriteringsprojekt som på ett mångsidigt sätt belyser tema-helheten "människan" under Finlands ordförandeskap för Nordiska ministerrådet. Vi söker innovativa lösningar och verksamhetsmodeller för att bevara välmående och jämlikhet $i$ en situation där våra samhällen utmanas från många håll: en allt äldre befolkning i Norden, strukturförändringar i närings- och arbetslivet, världspolitiska kriser och det globala läget med asylsökande.

Målsättningen med projektet är att bilda en gemensam, politiskt förankrad uppfattning om hur och under vilka förutsättningar vi i fortsättningen kan säkra ett nordiskt mervärde i det nordiska expertsamarbetet. Som ett mål på lång sikt är avsikten att stärka existerande forum och aktörer som arbetar för nordiskt samarbete i välfärdsfrågor och informationsspridning.

Välfärd, mångfald, jämlikhet, jämställdhet, funktionshinderfrågor och kulturellt hållbar utveckling är övergripande teman för hela projektet. Avsikten är att genomgående dra nytta av det nordiska forsknings- och innovationssamarbetet. Barn och unga är en särskild prioriterad målgrupp.

Kulturen spelar en viktig roll i människornas välmående och delaktighet. Under de senaste åren har antalet invandrare ökat i samtliga nordiska länder. Därigenom har den nordiska kulturen berikats och fått flera nya aspekter. Inom ramen för vårt prioriteringsprojekt inleds ett sektorövergripande projekt i syfte att öka invandrarnas delaktighet samt förbättra en ömsesidig integreringsprocess med hjälp av konst och kultur.

\section{EVENEMANG}

- Kick off-seminarium för det treåriga prioriteringsprojektet, 27-28 januari 2016 i Åbo.

- Ungdomscafé, 27 januari 2016 i Åbo. 

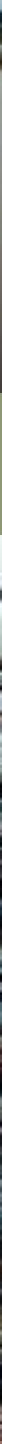


\section{Det hållbara Norden}

Det nordiska kulturlivet stärker de nordiska samhällenas hållbarhet med hjälp av tillgänglighet och engagerande verksamhet.

I samarbete med Kulturkontakt Nord (KKN) och CUPORE ordnar vi ett seminarium om Mångfald och hållbarhet $i$ dagens kulturpolitik i Norden.

Seminariet tar upp frågor kring hur principerna för en socialt, kulturellt och ekologiskt hållbart utveckling kan samverka för att förebygga att samhället polariseras. Hur kan vi påverka världen i mer hållbar riktning?

\section{EVENEMANG}

- Mångfald och hållbarhet i dagens kulturpolitik i Norden

- seminarium, november 2016 i Helsingfors.

\section{Det kreativa Norden}

Norden är ett vitalt, dynamiskt och kreativt kulturområde.

De nordiska länderna är världsberömda för sin arkitektur och design. Våra praktiska och högklassiga nordiska vardagsmiljöer har av tradition varit ett mått på vår livskvalitet och vårt internationella anseende.

De nordiska länderna är också i framkanten när det handlar om att utveckla och förnya arkitekturpolitiken. Finlands arkitekturpolitiska program (1998) har fått stå modell för motsvarande program i flera andra europeiska länder. Som ett led $i$ utarbetandet av ett den typens program samlas medborgare, experter, myndigheter och beslutsfattare för att tillsammans identifiera den byggda miljöns kulturella, sociologiska och ekologiska betydelse. Med stöd av dem tar man därefter fram riktlinjer fram för framtida trivsamma invånarmiljöer och lyckade platser.

I samarbete med "Architecture Information Centre Finland" ordnas ett seminarium i Helsingfors i början av hösten 2016 kring arkitekturens betydelse för den nordiska välfärden och konkurrenskraften.

\section{EVENEMANG}

- Arkitekturen som djupstruktur inom den nordiska kulturen och välfärden - seminarium, hösten 2016 i Helsingfors. 


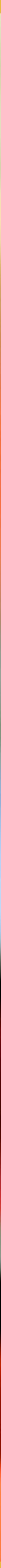




\section{Det interkulturella Norden}

Alla invånare i Norden känner sig hemma i Norden och är kulturellt delaktiga i Norden.

Invandringen och ojämlikheten mellan olika befolkningsgrupper är ett utmanande fenomen som bl.a. manifesteras i form av hatfylld retorik. Finland står värd för UNESCO:s World Press Freedom Day -konferens om yttrandefrihet den 3-4 maj 2016. Samtidigt firas världens första tryckfrihetsförordning som började tillämpas i Sverige år 1766.

UNESCO:s konferens lyfter fram vad pressfrihet betyder för att de mänskliga rättigheterna omsätts i praktiken, för ett fungerande medborgarsamhälle och demokratiutvecklingen. Centrala teman är bl.a. journalisternas säkerhet, tillgången till information, medialäskunnighet, utvandringen och den kulturella yttrandefriheten.

I samarbete med Hanaholmens kulturcentrum för Sverige och Finland, UNESCO och Finlands Nationalmuseum ordnas som ett sidoevenemang till själva UNESCO - konferensen ett seminarium kring Re-shaping Cultural Policies, i syfte att öka medvetenheten om vilken betydelse en mångfacetterad yttrandefrihet på kulturens område har för en hållbar utveckling och kulturella uttryck i Norden, samt hur man skulle kunna utnyttja dem i genomförandet av FN:S agenda för hållbar utveckling (Agenda 2030). Under seminariet diskuteras också vilken betydelse den digitala revolutionen har på konstens och kulturens område, från den kreativa ekonomins kreativa processer till tillgången på och distributionen av de verk som skapas.

UNESCO:s konferens kring yttrandefrihet är ett bra och globalt forum för de nordiska länderna där de kan uppträda tillsammans. I anslutning till konferensen ordnas även årets första kulturminstermöte.

\section{EVENEMANG}

- UNESCO:s konferens kring yttrandefrihet, 3-4 maj 2016 i Helsingfors. Re-shaping Cultural Policies - seminarium, 2 maj 2016 i Helsingfors.

- Kulturministermöte, 2 maj 2016 i Helsingfors. 


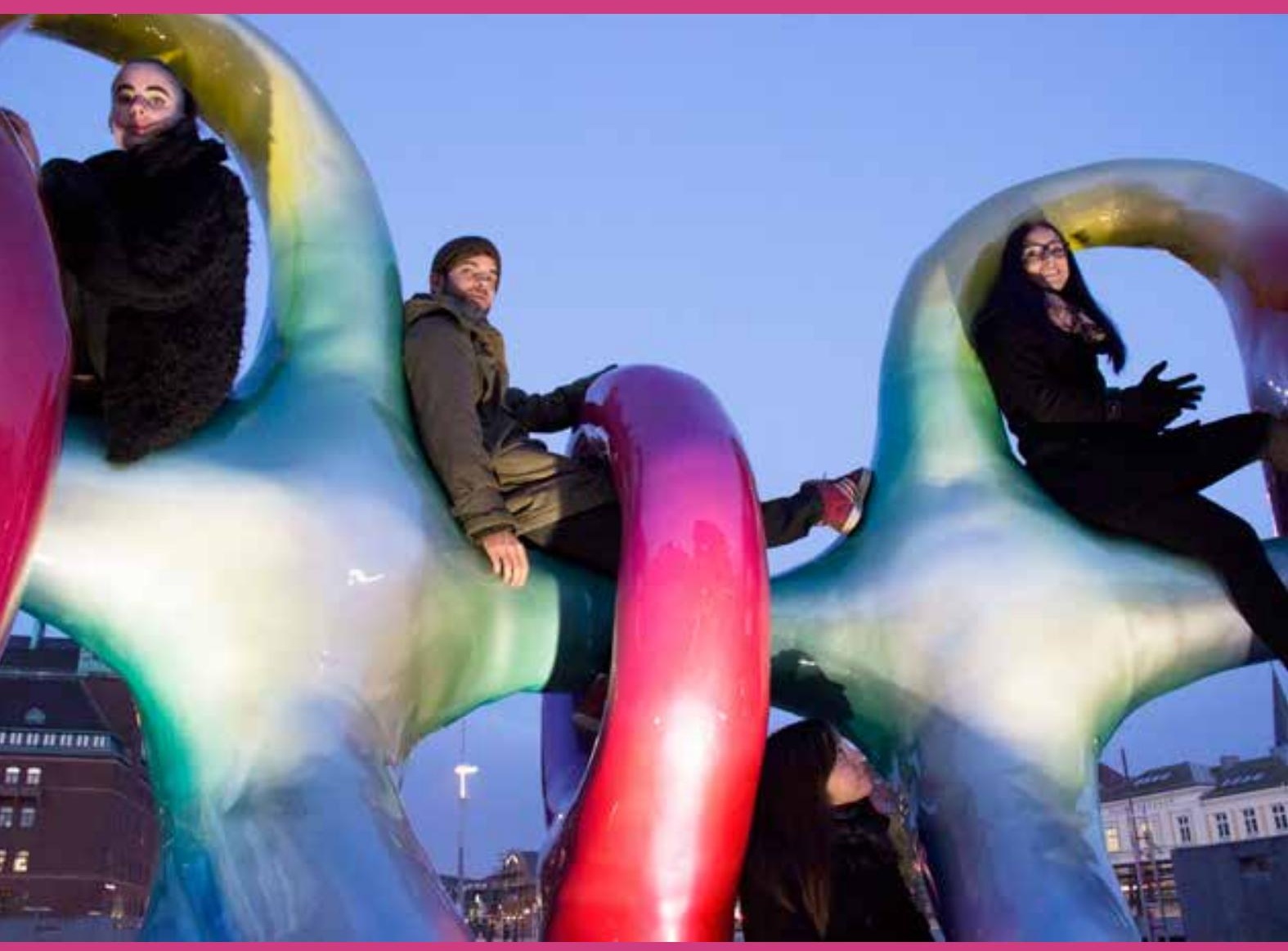




\section{Det unga Norden}

Barn och unga i Norden är kreativa, deltagande och har synpunkter om konst och kultur.

Barn och ungdomar har en viktig roll i det nordiska kultursamarbetet, som tillerkänner dem rätten och förutsättningarna för att påverka sitt eget liv. Det är också för deras skull det är viktigt att skapa både digitala och fysiska mötesplatser som motsvarar deras behov och önskemål.

Med tanke på såväl hur mångskiftande frågor det handlar som på principerna för hållbar utveckling är bra att utgå från en sektorövergripande modell i frågor som gäller barn och ungdomar.

Under ordförandeskapet ordnas i samarbete med bl.a. NORDBUK, socialoch hälsovårdsministeriet, arbets- och näringsministeriet, Kulturkontakt Nord (KKN) samt Hanaholmens kulturcentrum för Sverige och Finland ungdomskonferensen SILLAT-BRIDGES-BROAR-BROER kring ungas välmående och delaktighet i de nordiska länderna. Den sektorövergripande samarbetskonferensen granskar hur de ungas välfärd och rättigheter tillgodoses bl.a. ifråga om utbildning, jämställdhet, kultur och media samt sysselsättning och entreprenörskap.

\section{EVENEMANG}

- SILLAT-BRIDGES-BROAR-BROER - samnordisk ungdomskonferens, 26-28 september 2016 i Helsingfors. 


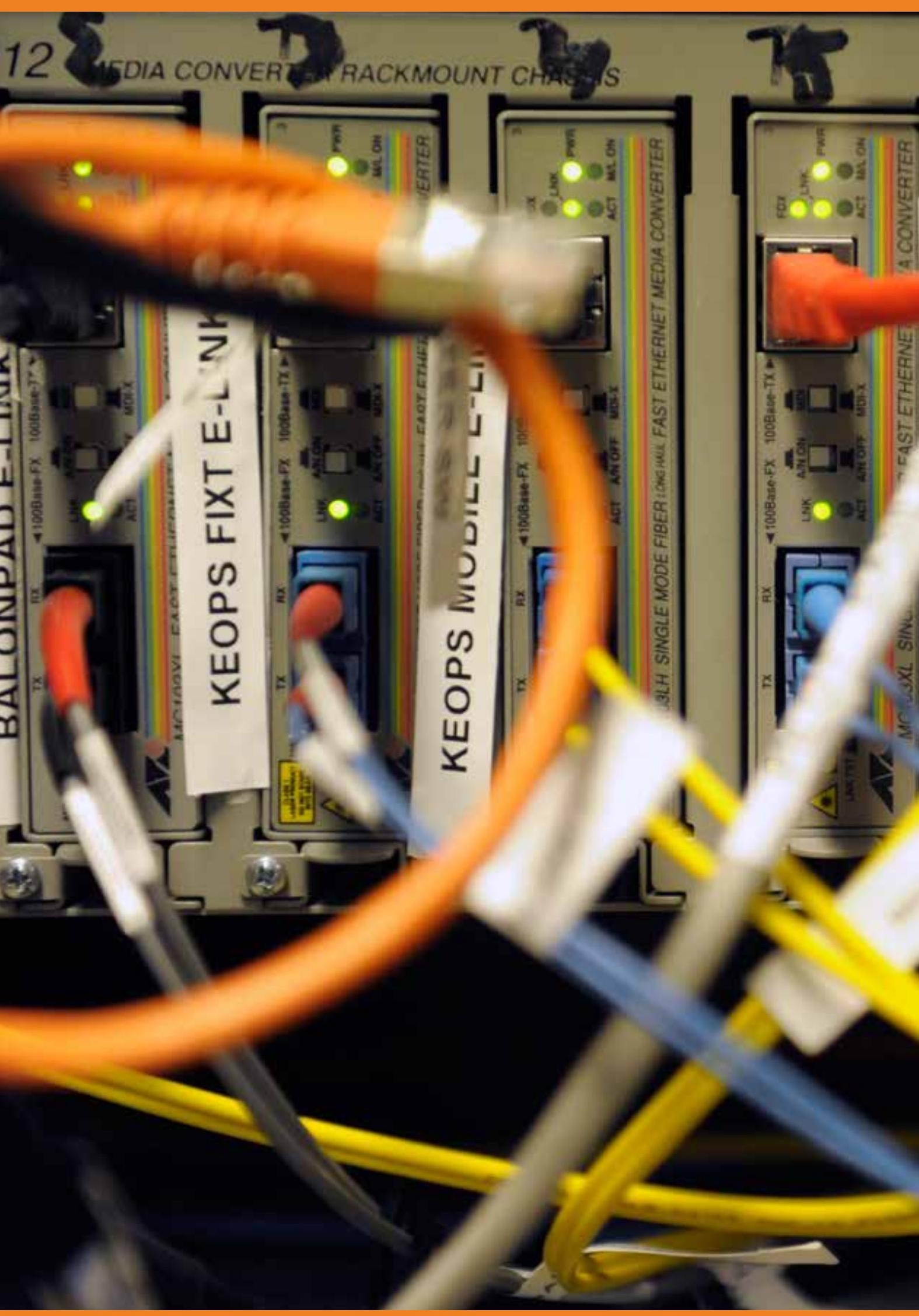




\section{Det digitala Norden}

Den nordiska kulturen utnyttjar hela potentialen av den digitala teknologin.

Kulturhistoriska museer har redan länge haft behov av att utveckla administrationen av samlingarna och dela upp arbetet kring detta samt av att dokumentera vår samtid. TAKO är ett nationellt samarbetsnätverk för dokumentations- och insamlingsarbete som leds av Finlands Nationalmuseum.

Nätverket har två centrala syften: arbetsfördelningen i fråga om datalagring samt samordningen av samtidsdokumentering.

Även om alla nordiska museer ägnar sig åt samtidsdokumentering, sker det inom lite olika nätverk. Att vi kan utbyta tankar om processerna för samtidsdokumentering och nätverken kring dem är en första rangens fråga, och därför ska det nationella nätverket utvidgas till ett samnordiskt nätverk under Finlands ordförandeskap. Seminariet fokuserar på de senaste aspekterna på utvecklingen inom samlingshantering samt de viktigaste utmaningarna på området, med särskild betoning på de premisser digitaliseringen fört med sig.

\section{EVENEMANG}

- Digitala samlingar - för ett öppnare Norden

- seminarium, 9-10 februari 2016 i Helsingfors. 


\section{Preliminärt kalendarium 2016}

\begin{tabular}{|c|c|c|}
\hline Evenemang & Tid & Ort \\
\hline $\begin{array}{l}\text { Kick-off - seminarium för det treåriga } \\
\text { prioriteringsprojektet }\end{array}$ & $27-28.1 .2016$ & Åbo \\
\hline Ungdomscafé & 27.1.2016 & Åbo \\
\hline $\begin{array}{l}\text { Ämbetsmannakommittémöte } \\
\text { (ÄK-K 1/16) }\end{array}$ & $2-3.2 .2016$ & Köpenhamn \\
\hline $\begin{array}{l}\text { Digitala samlingar - för ett öppnare Norden } \\
\text { - seminarium }\end{array}$ & $9-10.2 .2016$ & Helsingfors \\
\hline $\begin{array}{l}\text { Ämbetsmannakommittémöte } \\
\text { (ÄK-K 2/16) }\end{array}$ & $30-31.3 .2016$ & Helsingfors \\
\hline Kulturministermöte (MR-K 1/16) & 2.5 .2016 & Helsingfors \\
\hline $\begin{array}{l}\text { Sidoevenemang till UNESCO:s konferens om } \\
\text { yttrandefrihet, Re-shaping Cultural Policies } \\
\text { - seminarium om den kulturella yttrandefriheten }\end{array}$ & 2.5 .2016 & Helsingfors \\
\hline $\begin{array}{l}\text { UNESCO:s World Press Freedom Day } \\
\text { - konferens kring yttrandefrihet }\end{array}$ & $3-4.5 .2016$ & Helsingfors \\
\hline $\begin{array}{l}\text { Arkitekturen som djupstruktur i nordiska } \\
\text { kulturen och välfärden - seminarium }\end{array}$ & hösten 2016 & Helsingfors \\
\hline $\begin{array}{l}\text { Ämbetsmannakommittémöte } \\
\text { (ÄK-K 3/16) }\end{array}$ & vecka 37 & Åland \\
\hline $\begin{array}{l}\text { SILLAT-BRIDGES-BROAR-BROER } \\
\text { - samnordisk ungdomskonferens }\end{array}$ & $26-28.9 .2016$ & Helsingfors \\
\hline Kulturministermöte (MR-K 2/16) & 2.11 .2016 & Köpenhamn \\
\hline $\begin{array}{l}\text { Mångfald och hållbarhet i dagens kulturpolitik } \\
\text { i Norden - seminarium }\end{array}$ & november 2016 & Helsingfors \\
\hline $\begin{array}{l}\text { Ämbetsmannakommittémöte } \\
\text { (ÄK-K 4/16) }\end{array}$ & $1-2.12 .2016$ & Köpenhamn \\
\hline
\end{tabular}



Nordiska ministerrådet

Ved Stranden 18

DK-1061 København K

www.norden.org

\section{norden}

Nordiska ministerrådet

Finlands ordförandeskap 2016

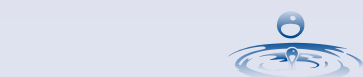

Sekretariatet

för nordiskt samarbete

Utrikesministeriet

www.norden2016.fi

Laivastokatu $22 \mathrm{H}$

FI-00160 Helsingfors

Telefon: +358295350000

\section{SUOMI}

FINLAND

ANP 2016:717

ISBN 978-92-893-4519-4 (PRINT)

ISBN 978-92-893-4520-0 (PDF) 